\title{
Pollen-embryogenesis and chromosomal variability in anther culture of Brassica hirta Moench (Sinapis alba $\mathrm{L}$ )
}

\author{
BAJAJ YPS* AND D MOHAPTRA** \\ *A-137 New Friends Colouy, New Delfi 110065, India \\ ${ }^{*}$ NARP, R.R.S, Ranital, Balasore Orissa 756111, India
}

\begin{abstract}
The anther cultures of Brassica hirta underwent poIlenembryogenesis and callusing, which showed a wide range of chromosome numbers varying from $9(\mathrm{n}=12)$ to a highly polyploid. For embryogenesis, pretreatment of floral buds in $0.4 \mathrm{M}$ sucrose solution for $72 \mathrm{hrs}$ at $4^{\circ} \mathrm{C}$ was superior to freshly cultured anthers. Culture temperature of $30^{\circ} \mathrm{C}$ for 14 days before maintenance of cultures at $25^{\circ} \mathrm{C}$ was significantly beneficial for embryo yield in comparison to cultures conlinuously incubated at $25^{\circ} \mathrm{C}$. Dark treatment during culture was more effective for pollen-embryo yield.
\end{abstract}

Key words: Pollen-embryogenesis, anther culture, Brasia hirta chromosomal variability.

\section{INTRODUCTION}

White mustard is an important oilseed crop. The in vitro induction of haploids, and the genetic variabiliby would considerably help to widen the genetic base for its further incorporation in other oilseed crop improvement programs. The significance of the in vitro induction of haploids [1, 2] and their utilization in oilseed Brassica breeding have been fairly emphasized $[3,4,5]$. In an earlier study the frequency of induced pollen embryos was very low E6], however it is necessary that the frequency of such events should be sufficiently high to enable their incorporation into breeding programs. The present investigation therefore deals with some of the factors enhancing pollen embryogenesis, and the induction of chromosomal variation in callus cultures.

\section{MATERIALS AND METHODS}

The seeds of white mustard, Brassica hirta Moenoh syn Sinapis alba L. were grown in the oilseed fields of the Punjab Agricultural Univeristy, Ludhiana during OctoberNovember, and normal agronomic practices were followed to raise the crop. The first produced young inflorescenees were collected from the healthy plants, and twe types of pretreatments were given, either (i) the excised inflorescences were inserted in a beaker of water, and kept in a refrigerator at $4^{\circ} \mathrm{C}$ for 7 days in the dark, or (ii) the flower buds were 
Pollen-embryogenesis and chromosomal varia bility in anther culture

kept in $0.4 \mathrm{M}$ sucrose solution and cold treated for 3 days in dark. The freshly colleoted anthers were cultured as the controls.

Flower buds (2-3 $\mathrm{mm}$ ) were sterilized in chlorine water for 4-5 minutes, and washed thoroughly in sterilized water. The anthers were excised from the buds and about 20 of them were cultured per test-tube. Most of the anthers were at the uninucleale stage. Three media were used for the culture i.e. (i) modified B5 medium [7] containing NAA (0.1 $\mathrm{mg} / 1)$ and 2, 4-D $(0.1 \mathrm{mg} / 1)$, (ii) modified $\mathrm{B}_{5}$ with NAA $(1 \mathrm{mg} / 1)+2$, 4-D (1 rag/l), and (iii) $\mathrm{MS}+\mathrm{NAA}(0.1 \mathrm{rag} / \mathrm{l})+\mathrm{BAP}(0.1 \mathrm{mg} / \mathrm{l})$. All manipulations were carried out aseptically in a laminar flow chamber.

The cultured anthers were incubated in both light and dark at $25^{\circ} \mathrm{C}$ continuously, and at $30^{\circ} \mathrm{C}$ for a period of 14 days prior to maintenance at $25^{\circ} \mathrm{C}$. The anthers were examined at weekly intervals for 8 weeks. The anthers and the calli were fixed periodically in acetic alcohol (acetic acid: alcohol, 1: 3), and acetoearmine squashing technique was followed to study embryogenesis and chromosome counts in the calli.

\section{RESULTS AND DISCUSSION}

The observations on the in vitro growth response of the excised anthers, effect of' various pretreatments on pollen embryogenesis, and the induction of variability in chromosome numbers are shown in Figures 1-3, and Table 1.

The excised anthers cultured on $\mathrm{B}_{5}$ medium initiated callus within 3 weeks (Fig. 2A), and in some cases they burst open and a mass of callus was formed in 5 weeks (Fig. 2B). If the callus was not transferred to other media, it had a tendency to undergo rhizogenesis, and sometimes the whole surface of the callus was covered with small and very fine roots (Fig. 2C).

A glance at Table 1 and Figure 2 shows the beneficial effect of various pretreatments of the floral buds on the frequency of embryogonesis. The cold treatment caused an increase in embryogenic anthers from $1.28 \%$ in the untreated anthers to $3.24 \%$ in the cold-treated ones. The cold treatment, though enhanced the frequency of pollen embryos, at the same time it reduced the in tensity of callusing. Whereas $20 \%$ of the anthers callused in the control, in the pretreated anthers it was reduced to only $8.4 \%$. The microscopic examination showed pollen at various stages of division of the nuclei (Fig, 2 D--F, Table 1 ). The frequency of uninucleate pollen was as high as $30.08 \%$, followed by binucleate $(5.27 \%)$, trinucleate $(1.28 \%)$, tetranucleate $(0.89 \%)$, multinucleate $(0.79 \%)$ and multicellular structures $(0.39 \%)$, the rest either degenerated or the nuclei could not be identified.

The beneficial role of temperature shocks on the induction of pollen-embryos is established $[8,9]$. The coldtreatment slows down the regular development of pollen and prevents their degeneration,which further depends on the temperature, duration of the cold treatment and varies wibh bho genotypes. In B. campestris, for instance $5^{\circ} \mathrm{C}$ for 7 days reduced embryo yield [5], whereas continuous treatment at $4^{\circ} \mathrm{C}$ for several days in B. napus was stimulatory [10]. Klimaszwski and Keller [6] reported that high temperature pretreatment $\left(35^{\circ} \mathrm{C}\right)$ for two days prior to maintenance at $25^{\circ} \mathrm{C}$ induced embryogenesis in B. hirta. We combined these two manipulations and pretreated the anthers at $47^{\circ} \mathrm{C}$ for $3-7$ days, followed by their 
culture at $30^{\circ} \mathrm{C}$ for 14 days, and Short incubating them at $25^{\circ} \mathrm{C}$. By doing so considerable increase was noticed. Various stress pretreatments have been suggested to increase embryogenosis [11]. In the present study prefreating the floral buds with $0.4 \mathrm{M}$ sucrose solution for 3 days at $4^{\circ} \mathrm{C}$ before culture greatly helped the embryo yield (Table 1).

Tab. 1. Effect of various pretreatments of the floral buds an the frequency of androgenic anthers in Brassica hirta

\begin{tabular}{lcccc}
\hline $\begin{array}{c}\text { Pretreatment } \\
\text { condition }\end{array}$ & $\begin{array}{c}\text { Duration of } \\
\text { treatment }\end{array}$ & $\begin{array}{c}\text { Number of } \\
\text { anthers } \\
\text { cultured }\end{array}$ & $\begin{array}{c}\text { Number of } \\
\text { embryogenic } \\
\text { anthers }\end{array}$ & $\begin{array}{c}\text { Frequency of } \\
\text { embryogenic } \\
\text { anthers( }) \%\end{array}$ \\
\hline $\begin{array}{l}\text { 1. } \text { Control } \\
\text { (no treatment) }\end{array}$ & - & 262 & 1 & 1.28 \\
2. $4^{\circ} \mathrm{C}$ in water & 7 days & 340 & 6 & 1.76 \\
3. $4^{\circ} \mathrm{C}$ in sucrose & 3 days & 432 & 14 & 3.24 \\
solution $(0.4 \mathrm{M})$ & & & & \\
\hline
\end{tabular}

The cytological evaluation of anther-derived calli established the existance of wide chromosomal variability. In addition to haploid $(n=12)$, largo number of hypo-, and hyperhaploid cells, along with aneuploids and polyploids were observed (Fig. 1, 3). The callus cells were predominantly diploid (up 6o $59 \%)$ followed by haploids $(26--47 \%)$, the numbers less than haploids or more than tetraploids varied between 1--4\%. Recently alomst similar observations have been made on anther culture of various grain legumes [12], and cotton [13].

The wide range of chromosomal variability in the anther-derived callus could possibly be utilized by raising plants from them. Since the callus cultures of Sinapis alba undergo differentiation to form shoots and somatic embryos $[14,15]$, there is a possibility of the regeneration of variant plants from cell cultures.

To conclude, the manifold increase in pollen-embryos by the cold treatment, and the wide range of chromosome numbers in the anther-derived callus would be helpful for the

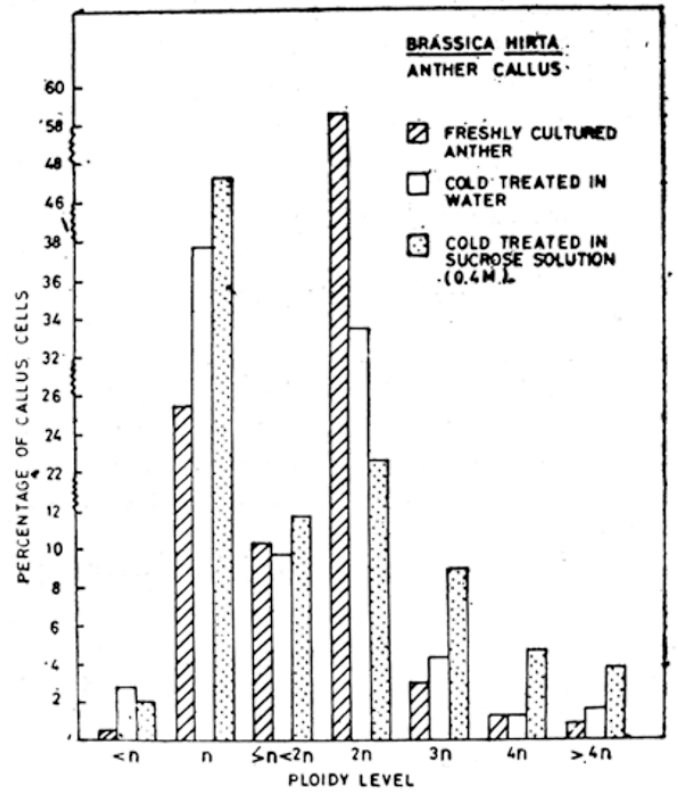

Fig. 1 Histogram showing the extent of genetic variability in anther-derived callus of $B$. hira after various treatments i.e. control (freshly cultured anthers), cold treated $\left(4^{\circ} \mathrm{C}\right)$ anthers in wa $\sim$ er, and cold treated in $0.4 \mathrm{M}$ sucrose solution for 3 days. production of increased numbers of haploids and variant plants, and for their further incorporation into oilseed Brassica improvement programs.

\section{ACKNO WLEDGEMENT}

This work was conducted under the research project "Crop Improvement through 

India.

\section{REFERENCES}

[1] Bajaj YPS. In vitro production of haploids. In: DA Evans, WR Sharp, PV Ammirato and Y Yamada eds Handbook of plant cell culture. Macmillan Press New York 1983: 228--287.

[2] Bajaj YPS. Haploids im crops improvement 1. In: Biotechnology in agriculture and forestry. Springer-Yerlag. Berlin Heidelberg New York Tokyo 1990: 12.

[ 3 ] Wenzel G, F Hoffmann and E Thomans. Anther culture as a breeding tool in rape. I. Ploidy level and phenotype of androgenetic plants. Z. Pflanzenzuchtg. 1977; 78: 149--155.

[4] Hoffann F, E Thomas and G Wenzel. Anther culture as a breeding tool in rape. II. Progeny analyses of androgenetic lines and induced mutans from haploid cultures. Theor. Appl. Genet. 1982; 61: 225--232.

[5] Keller WA, K0 Armstrong and AI La Roche. The production and utilization of microspore-derived haploids in Brassica, crops. In: SK Sen and KL Giles eds. Plant cell culture in crop improvement. Plenum Press New York 1983: 169--183.

[6] Klimaszewski K and WA Keller. The production of haploids from Brassica hirta Moench (Sinapis alba L. ) anther cultures. Z. Pflanzenphysiol. 1983; 109: 235--241.

[ 7 ] Keller WA and KC Armstrong. Embryogenesis and plant regeneration in Brassica napus anther culture. Can J Bot 1977; 55: 1383--1388.

[8] Reinert J and YPS Bajaj. Anther Culture: Haploid production and its significance. In: J Reinert and YPS Bajaj eds. Applied and fundamental aspects of plant cell, tissue, and organ culture. Springer-Verlag Berlin Heidelberg New York 1977: 251--267.

[9] Dunwell JM, M Gornish, AGL de Courcel and JE Middlefall-Williams, Induction and growth of 'microsporederived' embryos of Brassica napus sp. Oleifera J Exp Bet 1983; 34: 1768--1778.

[10] Lichter R. Induction of haploid plants from isolated pollen of Brassica napus. Z. Pflanzenphysiol 1982; 105: 427-434 .

[11] Sunderland N. Strateges in the improvement of yields in anther culture. In: Plant tissue culture. Proc Syrup Science Press Peking 1978: 65--86.

[12] Gosal SS and YPS Bajaj. Pollen embryogenesis and chromosomal variation in anther culture of three food legumes-Cicer arietinum, Pisum sativm and Vigna mun go. SABI AO J 1988;20:51--58.

[13] Bajaj YPS and MS Gill. Pollen-embryogenesis and chromosomal variation in anther culture of a diploid cotton (Gossypium arboreum L.) Sabrao J 1989; 21:57--63.

[14] Bajaj YPS and M Bopp. Growth and organ formation in Sinapis alba tissue cultures. Z. Pflanzenphysiol. 1972; 66: 378--381.

[15] Bajaj YPS, M Bopp and S Bajaj. Patterns of peroxidases and differentiation in Sinapis alba L. Phytomorphology 1973; 23: 43--52.

\section{Received 6-5-1990. Accepted 14.-6-1990.}



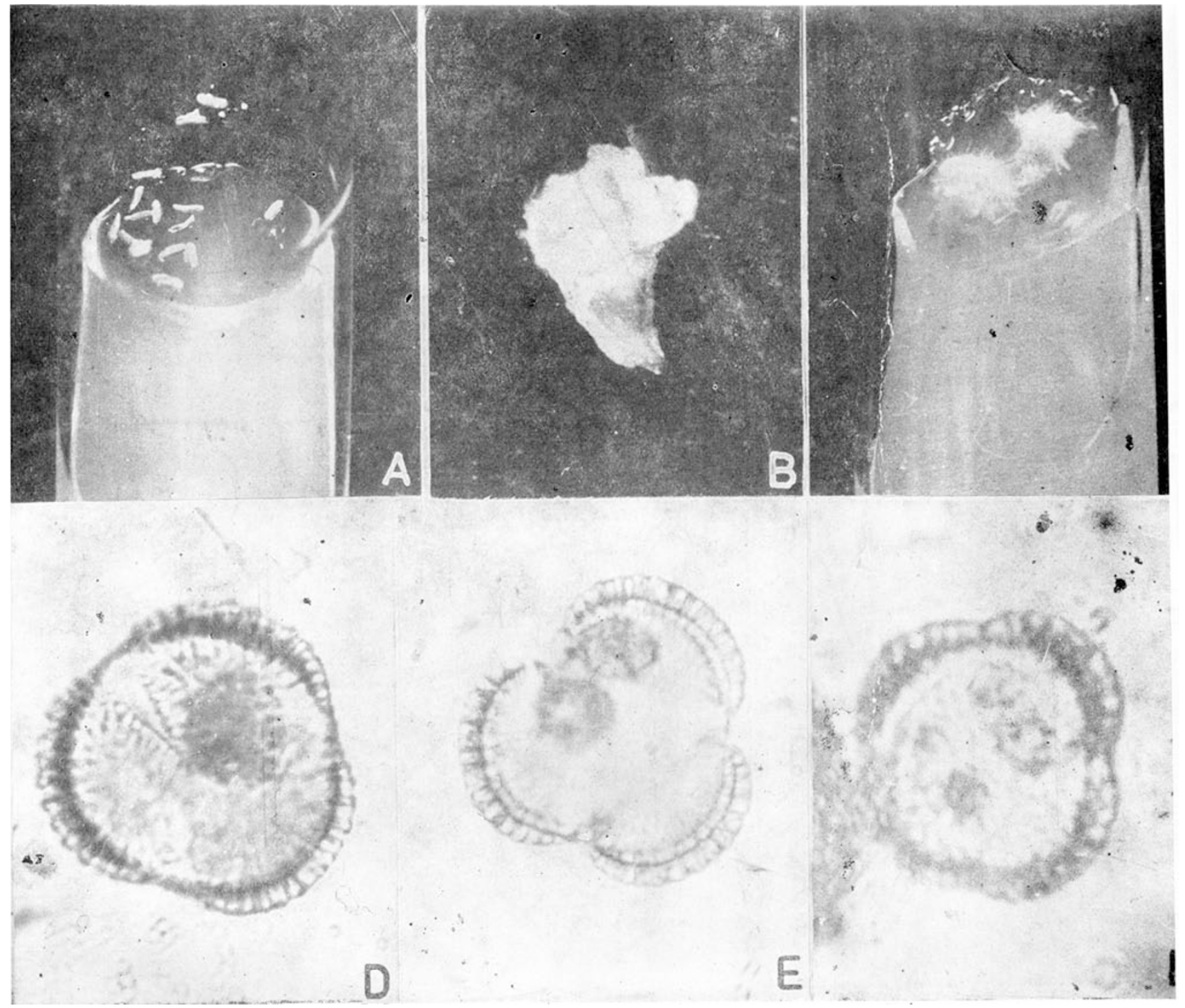

Fig.2 A-F. In vitro response of excised anthers of Brassica hirta cultured on modified $B_{5}$ medium. A. Anthers showing callus induction after 21 days of culture. B. Profuse callus, produced from the anther after 36 days of culture. G. Anther-derived callus producing roots after 40 days of culture. D--F. Uni-, hi-, and tetranucleate pollen from anthers of 21-day-old culture. 
Pollen-embryogenesis and chromosomal varia bility in anther culture

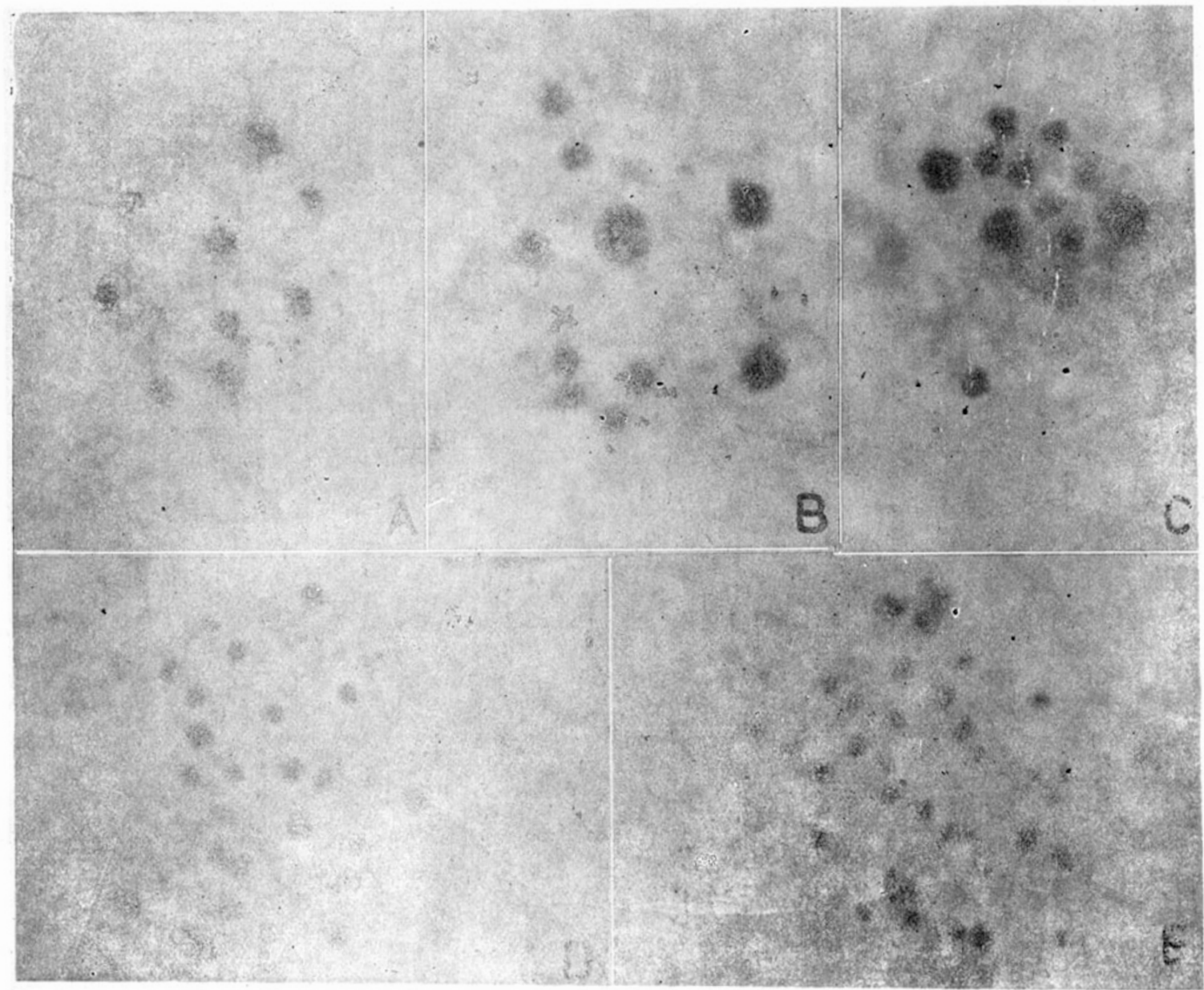

Fig.3 A-F. Extent of variability in chromosome number in anther-derived callus of B. hirta $(n=12)$, Cell showing 9(A), 10(B), 12(C), 24 (D) and.35(E) chromosome numbers. 